abrasive paper. Using metallographic techniques it has been established conclusively that the damage, produced in the surface layers of slices of germanium for use in semiconductor devices when cut from large single crystals and lapped to size, is due to cracks, and new methods of preparation of the slices which will considerably reduce the extent of the damage are being developed.
The annual report lists the various personnel of the Laboratories and their status, and gives details of the publications by members of the staff during the year under review. The staff numbered 687 on June 30, 1961. Open days were held at Maribyrnong during April 1961, and during the four days some 4,000 persons visited the Laboratories.

S. WeINTROUB

\title{
MENTAL HEALTH IN THE WORLD
}

$T$ is difficult to estimate the prevalence of mental illness, but in countries where services for the mentally ill are relatively highly developed, psychiatric cases account for almost half the total number of patients occupying hospital beds. Apart from cases in hospital, too, a considerable proportion of the world's population suffers from minor forms of mental ill-health which do not require hospitalization but may disorganize social relationships and productive capacity. It has been suggested that to provido satisfactory treatment for all cases of psychiatric disorder one psychiatrist is needed for every 20,000 people-a requirement that has so far been met in only a few areas.

The main concern of the World Health Organization in mental health has been to develop knowledge that can be applied in public health administration by its Member States. The reports of its Expert Committee on Mental Health and of its study groups on related subjects, for example, provide a conspectus of international views on policy in this field as they have developed over the past twelve years. Laying special emphasis on preventive work, the Organization has assisted the development of psychiatric services in Member States through seminars, conferences and fellowships and by providing consultants and expert advice. Its educational influence in mental health has been further extended by its publication of a number of authoritative studieson topics from the architecture of psychiatric hospitals to the epidemiology of mental disorders-by leading international authorities. The World Health Organization has also done much to foster both basic and applied psychiatric research.

A new booklet, which is a reprint of a series of articles that appeared in the WHO Chronicle between March and July 1962, surveys those aspects of mental health work with which the World Health Organization has been particularly concerned *. These include: the development of psychiatric services; the mental health tasks of the public health services; problems of prevention and treatment; education, training and research, and programme development. There is also a bibliography of World Health Organization reports and studies on mental health.

* World Health Organization. WHO and Mental Health, 1949-1961. Pp. 48. (Geneva : World Health Organization; London: H.M. Stationery Office, 1962.) I Swiss frane; $18.9 d . ; 0.30$ dollar.

\section{WIDESPREAD IONOSPHERIC DISTURBANCES DUE TO NUCLEAR EXPLOSIONS DURING OCTOBER 1961}

\author{
By Prof. TATSUZO OBAYASHI
}

\author{
lonosphere Research Laboratory, Kyoto University, Kyoto
}

A SERIES of Soviet nuclear tests made during October 1961 at Novaya Zemlya reveals the evidence of strong blast waves propagating through the ionosphere over a considerable distance. Two large nuclear tests were carried out at $08 \mathrm{~h} 28 \mathrm{~m}$ on 23 and at $08 \mathrm{~h} 33 \mathrm{~m}$ on October 30,1961 , which were probably of 30 and of 50 megatons, respectively. Although the exact situation of the tests at Novaya Zemlya is not known, the detonations were made probably in the troposphere. Some preliminary investigations on the remarkable ionospheric disturbances associated with these explosions have already been reported. At Scandinavian stations, the ionograms showed a sudden heavy disturbance in the $F$ region of the ionosphere about half an hour after the detonation ${ }^{1,2}$. A large increase of $f_{0} F_{2}$ and subsequent oscillatory variations with a period of $1 \frac{1}{2} h$ were found at Lindau, Germany, being delayed about $2 h^{3}$. Short-wave radio communications between Europe and Japan $(G B J-34,14 \cdot 80 \mathrm{Mc} / \mathrm{s}$, and $D G P-862$, $15.86 \mathrm{Mc} / \mathrm{s}$ ) deteriorated immediately and rather poor conditions lasted several hours ${ }^{4}$.

Similar ionospheric disturbances have been known at the high-altitude nuclear explosions over Johnston
Island during August 1958. The travelling $F_{2}$ disturbance was found which spread several thousand kilometres over the Pacific area ${ }^{5-7}$. Photographs of the explosion taken from Hawaii indicated clearly the existence of an expanding luminous front through the upper atmosphere ${ }^{8}$. Since these disturbances may possibly be due to shock waves spreading out from the explosion, the investigation of the present effect by the world-wide ionosonde network would be of great value. Thus, ionospheric data at about 30 stations in the northern hemisphere have been analysed.

The results for two events on October 23 and 30 , the time variations of $f_{0} F_{2}$ at several key stations in Europe and in Asia, and the field-strength record at the route Hamburg-Osaka $(15.86 \mathrm{Mc} / \mathrm{s})$ are illustrated in Fig. 1. The great-circle path of the HamburgOsaka is deviated about $1,000 \mathrm{~km}$ from the shot point. It is shown that an anomalously large increase and subsequent fluctuations of $f_{0} F_{2}$ were observed at all European stations, and smaller effects in Japan. The peak of increased $f_{0} F_{2}$ was delayed progressively from nearer to distant stations. This travelling disturbance was confirmed in India and in South-East Asia. Both 